\title{
Microscopic indicator for thermodynamic stability of hydrogen storage materials provided by positive muon-spin rotation
}

\author{
Jun Sugiyama, ${ }^{1, *}$ Yutaka Ikedo, ${ }^{1, \dagger}$ Tatsuo Noritake, ${ }^{1}$ Oren Ofer, ${ }^{2}$ Tatsuo Goko, ${ }^{2}$ Martin Månsson, ${ }^{3}$ Kazutoshi Miwa, ${ }^{1}$ \\ Eduardo J. Ansaldo, ${ }^{2}$ Jess H. Brewer, ${ }^{2,4}$ Kim H. Chow, ${ }^{5}$ and Shin-ichi Towata ${ }^{1}$ \\ ${ }^{1}$ Toyota Central Research and Development Laboratories Inc., Nagakute, Aichi 480-1192, Japan \\ ${ }^{2}$ TRIUMF, 4004 Wesbrook Mall, Vancouver, British Columbia, Canada V6T 2A3 \\ ${ }^{3}$ Laboratory for Neutron Scattering, Paul Scherrer Institut, ETH Zürich, CH-5232 Villigen PSI, Switzerland \\ ${ }^{4}$ Department of Physics and Astronomy, University of British Columbia, Vancouver, British Columbia, Canada V6T 1Z1 \\ ${ }^{5}$ Department of Physics, University of Alberta, Edmonton, Alberta, Canada T6G 2G7
}

(Received 18 January 2010; published 19 March 2010)

\begin{abstract}
In search of a high-capacity hydrogen storage system, we have investigated the thermodynamic properties of borohydrides $\left[M\left(\mathrm{BH}_{4}\right)_{2}\right]$. Using positive muon-spin rotation and relaxation $\left(\mu^{+} \mathrm{SR}\right)$, we have acquired data for five different powder samples below ambient temperature. Zero-field $\mu^{+} \mathrm{SR}$ measurements indicate the formation of the $\mathrm{H}-\mu^{+}-\mathrm{H}$ system in $\mathrm{LiBH}_{4}, \mathrm{NaBH}_{4}, \mathrm{KBH}_{4}$, and $\mathrm{Ca}\left(\mathrm{BH}_{4}\right)_{2}$ but not in $\mathrm{Mg}\left(\mathrm{BH}_{4}\right)_{2}$. It is also found that the amplitude of the $\mathrm{H} \mu \mathrm{H}$ signal $\left(A_{\mathrm{H} \mu \mathrm{H}}\right)$ varies with the electronegativity $\left(\chi_{\mathrm{P}}\right)$ of $M^{n+}$. Since the thermodynamic stability of $M\left(\mathrm{BH}_{4}\right)_{n}$ also depends on $\chi_{\mathrm{P}}, A_{\mathrm{H} \mu \mathrm{H}}$ is thought to be a microscopic indicator for the stability of $M\left(\mathrm{BH}_{4}\right)_{n}$.
\end{abstract}

DOI: 10.1103/PhysRevB.81.092103

PACS number(s): 82.33.Pt, 61.66.Fn, 65.40.-b, 76.75.+i

Vehicular applications of fuel cells face several huge barriers, among which the key component is still a safe, light, high-capacity hydrogen storage system, despite a long history of research into hydrogen storage materials. ${ }^{1}$ All the alloys that are currently used, including the Ti-based compounds, have a disadvantage for practical applications due to their small gravimetric $\mathrm{H}_{2}$ density, which makes them too heavy to carry on automobiles. It is well recognized that complex borohydrides are possible candidates for future onboard hydrogen storage materials, ${ }^{2,3}$ however, their slow dehydrogenation kinetics and high operating temperature (for releasing $\mathrm{H})$, i.e., hydrogen desorption temperature $\left(T_{\mathrm{d}}\right)$ need to be drastically improved if they are to enable a practical hydrogen storage system. Furthermore, although the dehydrogenation and rehydrogenation are known to involve multiprocess reactions, their mechanisms are still not fully understood. ${ }^{4,5}$ For instance, $\mathrm{LiBH}_{4}$, which exhibits the highest gravimetric $\mathrm{H}_{2}$ density (18.5 mass \%), liberates three of four hydrogen atoms and decomposes into $\mathrm{LiH}$ and boron through four intermediate states. ${ }^{6}$ However, only one intermediate state $\mathrm{Li}_{2}\left(\mathrm{~B}_{12} \mathrm{H}_{12}\right)$ has been characterized ${ }^{4,7}$ so far.

The nature of the "hydrogen bond" between positive muons $\left(\mu^{+}\right)$and anions has been extensively investigated by a positive muon-spin rotation and relaxation $\left(\mu^{+} \mathrm{SR}\right)$ technique since the discovery of the $\mathrm{F}^{-} \mu^{+} \mathrm{F}^{-}$(or " $\mathrm{F} \mu \mathrm{F}$ ") ion in metal fluoride crystals such as $\mathrm{LiF}, \mathrm{NaF}, \mathrm{CaF}_{2}$, and $\mathrm{BaF}_{2} \cdot{ }^{8}$ The $\mathrm{F} \mu \mathrm{F}$ system is easily identified via its characteristic muon-spin oscillation signal in a zero magnetic field $(\mathrm{ZF})$ $\mu^{+} \mathrm{SR}$ spectrum due to a dipole-dipole coupling in the collinear ${ }^{19} \mathrm{~F}-\mu^{+}-{ }^{19} \mathrm{~F}$ spin system. The $\mathrm{F} \mu \mathrm{F}$ system has also been found in organic polymers, e.g., Teflon ${ }^{9}$ and Nafion, ${ }^{10}$ despite a lack of crystal symmetry in these polymers. The formation of the $\mathrm{F} \mu \mathrm{F}$ system is thus a rather common phenomenon in compounds containing $\mathrm{F}^{-}$ions. ${ }^{11,12}$ Similar hydrogen bond systems with other anions, e.g., " $\mathrm{H} \mu{ }^{+} \mathrm{H}^{\prime}$ and/or " $\mathrm{H} \mu \mu^{+}$" have been reported in a Kagomé compound $\mathrm{ZnCu}_{3}(\mathrm{OH})_{6} \mathrm{Cl}_{3}$ (Ref. $13)$ in a layered cobalt dioxide $\left[\mathrm{Ca}_{0.85} \mathrm{OH}\right]_{1.16}\left[\mathrm{CoO}_{2}\right]$ (Ref.
14) and in $\mathrm{NaAlH}_{4}$, ${ }^{15}$ the last of which was studied as a potential hydrogen storage material for fuel cells.

In $\mathrm{NaAlH}_{4}$, the volume fraction of $\mathrm{H} \mu \mathrm{H}\left(V_{\mathrm{H} \mu \mathrm{H}}\right)$ was found to decrease by the Ti doping via a comparative $\mu^{+} \mathrm{SR}$ study on pure and Ti-doped $\mathrm{NaAlH}_{4}{ }^{15}$ Since $T_{\mathrm{d}}$ also decreases with the Ti doping, ${ }^{16} V_{\mathrm{H} \mu \mathrm{H}}$ was proposed as an indicator for the dehydrogenation kinetics of hydrogen storage materials. ${ }^{15}$ However, only one doped sample was examined and its $T_{\mathrm{d}}$ was not reported in Ref. 15. It is, thus, difficult to know the quantitative relationship between $V_{\mathrm{H} \mu \mathrm{H}}$ and the thermodynamic stability for $\mathrm{NaAlH}_{4}$. Furthermore, although the discovery of $\mathrm{H} \mu \mathrm{H}$ demonstrates that $\mu^{+} \mathrm{SR}$ can contribute significantly to research in hydrogen storage materials, $\mathrm{NaAlH}_{4}$ is unlikely to be a good solution for future onboard systems, due to its relatively small gravimetric $\mathrm{H}_{2}$ density (compared to $\mathrm{LiBH}_{4}$ ) and its insufficient rehydrogenation capacity. We have, therefore, performed a systematic $\mu^{+} \mathrm{SR}$ investigation of all the five $M\left(\mathrm{BH}_{4}\right)_{n}$ systems, for which pure powder samples are available. We have found that the $\mathrm{H} \mu \mathrm{H}$ system is a unique probe of both structural and dynamic/ kinematic properties of $\mathrm{H}$ in these compounds.

Powder samples of $\mathrm{LiBH}_{4}, \mathrm{NaBH}_{4}, \mathrm{KBH}_{4}$, and $\mathrm{Ca}\left(\mathrm{BH}_{4}\right)_{2}$ were purchased from Aldrich Co. Ltd. and $\mathrm{Mg}\left(\mathrm{BH}_{4}\right)_{2}$ from FZK (Forschungszentrum Karlsruhe). Since the samples are unstable in air, they were packed in an In- or Au-sealed aluminum powder cell in an Ar-filled glove box. The $\mu^{+} \mathrm{SR}$ experiments were performed on the M20 surface muon beamline at TRIUMF, using an experimental setup and techniques described elsewhere. ${ }^{17}$

Figure 1(a) shows the temperature $(T)$ variation in the $\mathrm{ZF}-\mu^{+} \mathrm{SR}$ time spectrum for $\mathrm{LiBH}_{4}$ in the $T$ range between 5 and $250 \mathrm{~K}$. One can clearly see a damped oscillation, particularly below $150 \mathrm{~K}$. Since there are no magnetic moments in $\mathrm{LiBH}_{4}$, such oscillation indicates the formation of the $\mathrm{H} \mu \mathrm{H}$ system in $\mathrm{LiBH}_{4}$. In fact, the ZF spectrum is well fitted by a combination of the $\mathrm{H} \mu \mathrm{H}$ signal, a static Gaussian KuboToyabe $\left(G_{\mathrm{KT}}\right)$ signal (from other muon sites experiencing 

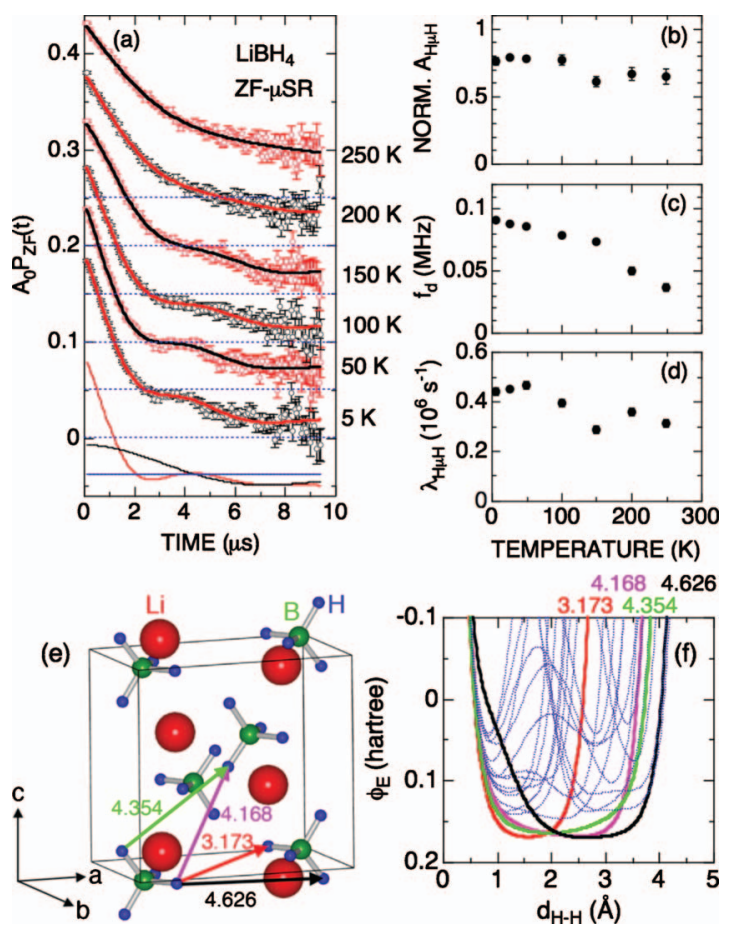

FIG. 1. (Color) Temperature dependence of (a) the ZF- $\mu^{+} \mathrm{SR}$ time spectrum for $\mathrm{LiBH}_{4}$, (b) the normalized $A_{\mathrm{H} \mu \mathrm{H}}$, (c) $f_{\mathrm{d}}$, (d) $\lambda_{\mathrm{H} \mu \mathrm{H}}$, crystal structure of (e) orthorhombic $\mathrm{LiBH}_{4}$ below $\sim 381 \mathrm{~K}$, and (f) the calculated electrostatic potential $\left(\phi_{\mathrm{E}}\right)$ along the $\mathrm{H}-\mathrm{H}$ bond in the distance range between 2.45 and $4.69 \AA$ in which 21 combinations are included. Bold solid lines in (a) represent the fitting result using Eq. (1) and the bottom three solid lines show the three components in Eq. (1). Each spectrum is offset by 0.05 for clarity of display. The $\mu^{+}$SR parameters in (b)-(d) were obtained by fitting the ZF- $\mu^{+}$SR time spectra using Eq. (1). Error bars in (c) are comparable to or below the size of solid circles. Arrows and numbers in (e) represent the distance to the neighboring hydrogen atoms, at the center of which $\mu^{+}$locates, based on the prediction from the $\phi_{\mathrm{E}}$ calculations. In (f), the lowest $4 \phi_{\mathrm{E}}$ 's are represented by a bold line while the rest 17 by a narrow (blue) dotted line.

disordered magnetic fields due to nuclear moments), and a background $(\mathrm{BG})$ signal from the powder cell (which is made of high-purity aluminum),

$$
A_{0} P_{\mathrm{ZF}}(t)=A_{\mathrm{H} \mu \mathrm{H}} P_{\mathrm{H} \mu \mathrm{H}}(t) \exp \left(-\lambda_{\mathrm{H} \mu \mathrm{H}} t\right)+A_{\mathrm{KT}} G_{\mathrm{KT}}(t)+A_{\mathrm{BG}} .
$$

Here, $A_{0}$ is the initial $(t=0)$ asymmetry, $P_{\mathrm{ZF}}(t)$ is the muonspin-polarization function in $\mathrm{ZF}, A_{\mathrm{H} \mu \mathrm{H}}, A_{\mathrm{KT}}$, and $A_{\mathrm{BG}}$ are the asymmetries of the three signals, $\lambda_{\mathrm{H} \mu \mathrm{H}}$ is the exponential relaxation rate of the precessing signal, and $\sigma_{\mathrm{G}}$ is the Gaussian relaxation rate. Here, $P_{\mathrm{H} \mu \mathrm{H}}(t)$ is the muon-spin-relaxation function caused by a colinear three spin $1 / 2$ system, given in Ref. 8,

$$
\begin{aligned}
P_{\mathrm{H} \mu \mathrm{H}}(t)= & \frac{1}{2}+\frac{1}{6} \cos \left(\sqrt{3} \omega_{\mathrm{d}} t\right)+\frac{1+1 / \sqrt{3}}{6} \cos \left(\frac{3+\sqrt{3}}{2} \omega_{\mathrm{d}} t\right) \\
& +\frac{1-1 / \sqrt{3}}{6} \cos \left(\frac{3-\sqrt{3}}{2} \omega_{\mathrm{d}} t\right)
\end{aligned}
$$

where $\omega_{\mathrm{d}}$ is the muon precession frequency due to the nuclear dipole field of the proton in the H- $\mu^{+}$bond. From $\omega_{\mathrm{d}}$, it is possible to calculate the distance $r$ between the $\mu^{+}$and the nucleus according to Ref. 8,

$$
\omega_{\mathrm{d}} \equiv 2 \pi \cdot f_{\mathrm{d}}=\mu_{0} \hbar \frac{\gamma_{\mu} \gamma_{N}}{4 \pi r^{3}}
$$

Here, $\gamma_{\mu}$ is the gyromagnetic ratio of $\mu^{+}$and $\gamma_{N}$ is the nuclear gyromagnetic ratio of ${ }^{1} \mathrm{H}$. Finally, $G_{\mathrm{KT}}$ is given by $G_{\mathrm{KT}}(t)=\frac{1}{3}+\frac{2}{3}\left(1-\Delta^{2} t^{2}\right) \exp \left(-\frac{\Delta^{2} t^{2}}{2}\right)$, where $\Delta$ is the field distribution width at the muon site. ${ }^{17}$

Figures 1(b)-1(d) show the $T$ dependences of the $\mu^{+}$SR parameters for $\mathrm{LiBH}_{4}$. The normalized $A_{\mathrm{H} \mu \mathrm{H}}\left[N_{A_{\mathrm{H} \mu \mathrm{H}}}\right.$ $\left.=A_{\mathrm{H} \mu \mathrm{H}} /\left(A_{\mathrm{H} \mu \mathrm{H}}+A_{\mathrm{KT}}\right)=V_{\mathrm{H} \mu \mathrm{H}}\right]$ reaches $\sim 0.8$ at $5 \mathrm{~K}$ and decreases monotonically with increasing $T$. However, even at $250 \mathrm{~K}, N_{A_{\mathrm{H} \mu \mathrm{H}}} \sim 0.6$. As $T$ increases from $5 \mathrm{~K}, f_{\mathrm{d}}$ also decreases monotonically up to $280 \mathrm{~K}$, which means that the increase in $r$ with $T$ is probably connected to thermal fluctuations/vibrations of the $\mathrm{BH}_{4}$ anions. Using Eq. (3), $2 r$ is estimated to be 3.16-4.42 $\AA$. According to electrostatic potential $\left(\phi_{\mathrm{E}}\right)$ calculations using a first-principles calculation based on density-functional theory with generalized gradient approximation method, ${ }^{18}$ there are four stable $\mu^{+}$sites for the $\mathrm{H} \mu \mathrm{H}$ system; namely, the center between the neighboring hydrogen atoms with the distance $d_{\mathrm{H}-\mathrm{H}}=3.173,4.168,4.354$, and $4.626 \AA$ [Figs. 1(e) and 1(f)]. These values are in good agreement with $2 r$ estimated from $f_{\mathrm{d}}$, indicating the change in occupancy of $\mu^{+}$at the center of the four $d_{\mathrm{H}-\mathrm{H}}$ with $T$. Particularly, since $2 r=3.16 \AA$ at $5 \mathrm{~K}, \mu^{+}$locates at the center of the shortest $d_{\mathrm{H}-\mathrm{H}}$ among four stable sites in the ground state. The monotonic decrease in $\lambda_{\mathrm{H} \mu \mathrm{H}}$ with $T$ implies an increase in homogeneity of the local (nuclear magnetic) environment caused by thermal fluctuation/vibration. This is consistent with the $T$ dependences of $N_{A_{\mathrm{H} \mu \mathrm{H}}}$ and $f_{\mathrm{d}}$. It should be noted that $\mu^{+}$starts to diffuse at high $T$, at which its thermal energy is comparable to the barrier energy between the potential minima. In order to clarify such diffusive behavior, we need to measure ZF spectra above $250 \mathrm{~K}$ together with longitudinal field spectra to distinguish the $\mu^{+}$motion from the $\mathrm{H} \mu \mathrm{H}$ signal.

In order to learn the nature of the $\mathrm{H} \mu^{+} \mathrm{H}$ system in other borohydrides, Fig. 2 shows the ZF spectrum for $\mathrm{LiBH}_{4}$, $\mathrm{NaBH}_{4}, \mathrm{MgBH}_{4}, \mathrm{KBH}_{4}$, and $\mathrm{CaBH}_{4}$ at $5 \mathrm{~K}$. Except for $\mathrm{MgBH}_{4}$, all the $\mathrm{ZF}$ spectra exhibit oscillations, indicating formation of an $\mathrm{H} \mu \mathrm{H}$ unit. Note that $A_{0} \sim 0.24$ for the present experimental setup. This means that some muons form a muonium $\left(\mu^{+} e^{-}\right)$state, which reduces $A_{0}$, as in the case for $\mathrm{NaAlH}_{4} \cdot{ }^{15}$ This is because all the borohydrides are a dielectric ionic crystal. The results of fits to the $\mathrm{ZF}$ spectra obtained at $5 \mathrm{~K}$ are summarized in Table I. In contrast to $\mathrm{LiBH}_{4}$, there are mainly two muon sites for the $\mathrm{H} \mu \mathrm{H}$ system in the tetrahedral $\mathrm{NaBH}_{4}$ lattice. The estimated $r$ suggests that the $\mu^{+}$is located at the center of the second-nearestneighboring hydrogen atoms [3.367 ̊ away, Fig. 3(d)].

Furthermore, we found a dynamic change in the $\mathrm{H} \mu \mathrm{H}$ signal accompanying a structural phase transition of $\mathrm{NaBH}_{4}$ at $T_{\mathrm{c}}=189.9 \mathrm{~K}$ from a low- $T$ tetragonal phase to a high- $T$ cubic phase due to an order-disorder transition of the $\mathrm{BH}_{4}$ 


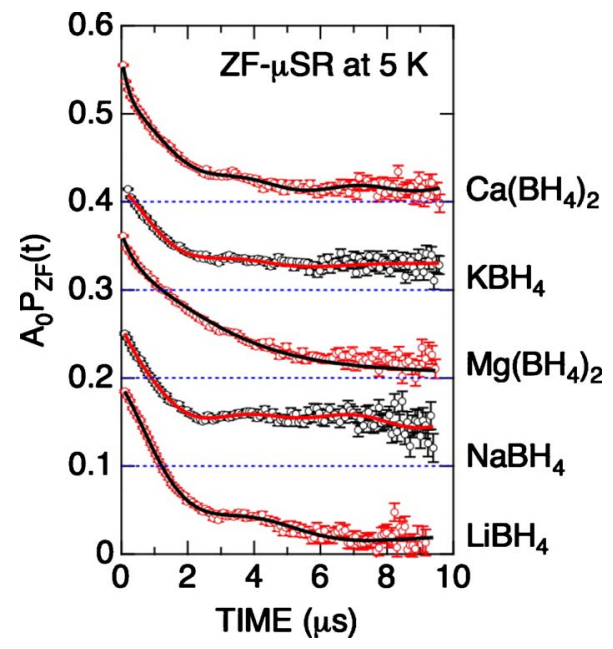

FIG. 2. (Color online) $\mathrm{ZF}-\mu^{+} \mathrm{SR}$ time spectra for $\mathrm{LiBH}_{4}$, $\mathrm{NaBH}_{4}, \mathrm{Mg}\left(\mathrm{BH}_{4}\right)_{2}, \mathrm{KBH}_{4}$, and $\mathrm{Ca}\left(\mathrm{BH}_{4}\right)_{2}$ at $5 \mathrm{~K}$. Solid lines represent the fitting result using Eq. (1). Each spectrum is offset by 0.1 for clarity of display.

tetrahedra [Figs. 3(d) and 3(e)]. ${ }^{19-21}$ The $\mathrm{H} \mu \mathrm{H}$ system is stable in the ordered state but would be unstable in the disordered state due to the rotation of the $\left[\mathrm{BH}_{4}\right]^{-}$group (Fig. 3). We, therefore, fitted the ZF spectrum using Eq. (1) plus an additional $\mathrm{H} \mu$ signal $\left[A_{\mathrm{H} \mu} P_{\mathrm{H} \mu}(t) \exp \left(-\lambda_{\mathrm{H} \mu} t\right)\right]{ }^{9,22}$ This means

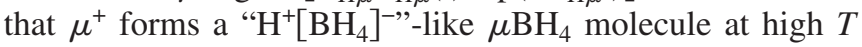
instead. In addition, despite the fact that the transition is thought to be second order, the present $\mu^{+} \mathrm{SR}$ result suggests the presence of the $\mu\left[\mathrm{BH}_{4}\right]$ state even below $T_{\mathrm{c}}$, probably due to microscopic vibration/rotation of the $\mathrm{BH}_{4}$ tetrahedra.

Although structural considerations are likely to explain the magnitude of $N_{A_{\mathrm{H} \mu \mathrm{H}}}$ for $\mathrm{LiBH}_{4}, \mathrm{NaBH}_{4}$, and $\mathrm{KBH}_{4}$, they offer no acceptable reasons for the absence of the $\mathrm{H} \mu \mathrm{H}$ signal in $\mathrm{Mg}\left(\mathrm{BH}_{4}\right)_{2}$ and the rather small $N_{A_{\mathrm{H} \mu \mathrm{H}}}$ in $\mathrm{Ca}\left(\mathrm{BH}_{4}\right)_{2}$. We, therefore, wish to discuss the stability of $N_{A_{\mathrm{H} \mu \mathrm{H}}}$ from another viewpoint. According to theoretical and experimental work on the thermodynamic stability of $M\left(\mathrm{BH}_{4}\right)_{n}(M=\mathrm{Li}$, $\mathrm{Na}, \mathrm{Ca}, \mathrm{Mg}, \mathrm{Zn}$, and $\mathrm{Sc})$, the stability of $M\left(\mathrm{BH}_{4}\right)_{n}$ is likely to show a good correlation with the electronegativity $\left(\chi_{\mathrm{P}}\right)$ of cations $M^{n+}$ [Fig. 4(a)], ${ }^{23}$ that is, larger $\chi_{\mathrm{P}}$, implies less thermodynamic stability. This indicates that, although the bonding between $M^{n+}$ and $n\left[\mathrm{BH}_{4}\right]^{-}$is basically ionic, the charge transfer from $\left[\mathrm{BH}_{4}\right]^{-}$to $M^{n+}$ is a key feature for the stability of $M\left(\mathrm{BH}_{4}\right)_{n}$. This situation is thus expected to be drastically
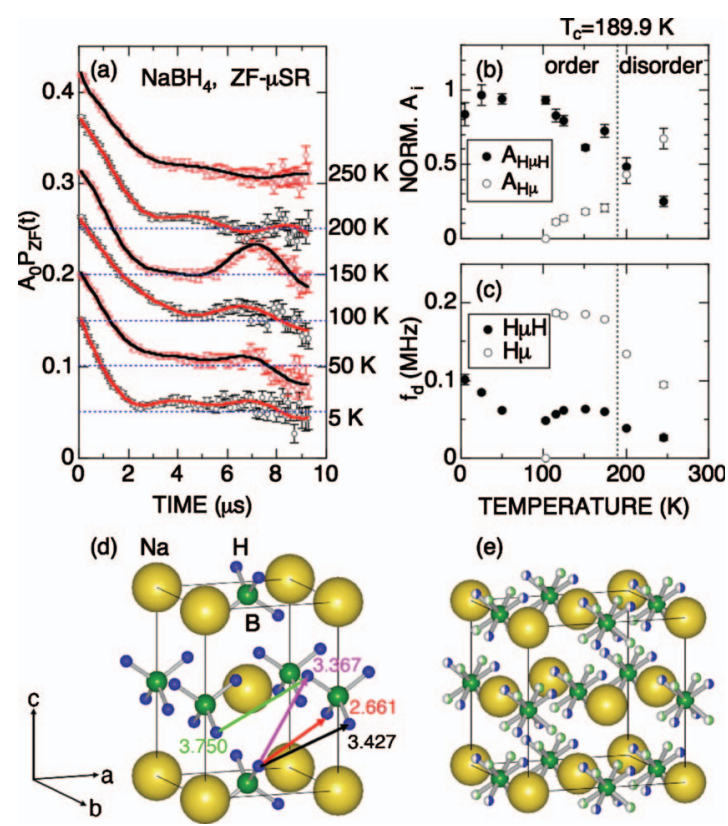

(e)

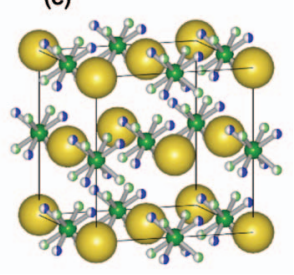

FIG. 3. (Color) Temperature dependences of (a) the ZF- $\mu^{+} \mathrm{SR}$ time spectrum for $\mathrm{NaBH}_{4}$, (b) $N_{A_{\mathrm{H} \mu \mathrm{H}}}$ and $N_{A_{\mathrm{H} \mu}}$, and (c) $f_{\mathrm{d}}$, and the crystal structure (d) below and (e) above $T_{\mathrm{c}}=189.9 \mathrm{~K}$. In (a), the solid lines represent the fitting result using Eq. (1) plus an additional $\mathrm{H} \mu$ signal (Ref. 9). Each spectrum in (a) is offset by 0.05 for clarity of display.

changed if the liberated $\mathrm{H}$ ions are coupled with the neighboring $\left[\mathrm{BH}_{4}\right]^{-}$anions. In other words, the stability of the $\mathrm{H} \mu^{+} \mathrm{H}$ system in $M\left(\mathrm{BH}_{4}\right)_{n}$ should also be a good indicator for their performance of dehydrogenation. In fact, one can clearly see a good correlation between $T_{\mathrm{d}}$ and $N_{A_{\mathrm{H} \mu \mathrm{H}}}$ [Fig. 4(b)], where $T_{\mathrm{d}}$ was determined by thermal-desorption spectroscopy measurements using gas chromatography. ${ }^{23}$

As already proposed by Kadono et al., ${ }^{15}$ protonlike hydrogen atoms would be generated during the desorption reaction of $M\left(\mathrm{BH}_{4}\right)_{2}$. In order to accelerate this reaction, the generated hydrogen atoms should be removed from the materials through a solid-state diffusion process. The presence of a stable $\mathrm{H} \mu \mathrm{H}$ (and/or $\mathrm{H} \mu$ ) system indicates the formation of a $\left[\mathrm{BH}_{4}\right]^{-}-\mathrm{H}^{+}-\left[\mathrm{BH}_{4}\right]^{-}$(and/or $\mathrm{H}^{+}-\left[\mathrm{BH}_{4}\right]^{-}$) bond in $M\left(\mathrm{BH}_{4}\right)_{2}$ during the desorption reaction. Since such a bond clearly reduces the reaction rate, it is expected that additional thermal energy is necessary to decompose the $M\left(\mathrm{BH}_{4}\right)_{2}$ with

TABLE I. $\mu^{+}$SR parameters obtained by fitting the ZF spectra at $5 \mathrm{~K}$ using Eqs. (1)-(3). For $\mathrm{Mg}\left(\mathrm{BH}_{4}\right)_{2}$, since $f_{d}=0, N_{A_{\mathrm{H} \mu \mathrm{H}}}=0$. However, for such case, the first term of Eq. (1) is equivalent to $A_{\mathrm{e}} \exp \left(-\lambda_{\mathrm{e}} t\right)$, as indexed by $*$ and $* *$.

\begin{tabular}{|c|c|c|c|c|c|c|}
\hline$M$ for $M^{n+}\left(\mathrm{BH}_{4}\right)_{n}$ & $N_{A_{\mathrm{H} \mu \mathrm{H}}}$ & $\begin{array}{c}f_{\mathrm{d}} \\
(\mathrm{MHz})\end{array}$ & $\begin{array}{l}2 r \\
(\AA)\end{array}$ & $\begin{array}{c}\lambda_{\mathrm{H} \mu \mathrm{H}} \\
\left(10^{6} \mathrm{~s}^{-1}\right)\end{array}$ & $N_{A_{\mathrm{KT}}}$ & $\begin{array}{c}\Delta \\
\left(10^{6} \mathrm{~s}^{-1}\right)\end{array}$ \\
\hline $\mathrm{Li}$ & $0.79(4)$ & $0.095(5)$ & $3.19(6)$ & $0.44(2)$ & $0.21(4)$ & $0.29(5)$ \\
\hline $\mathrm{Na}$ & $0.83(8)$ & $0.101(7)$ & $3.12(7)$ & $0.45(5)$ & $0.17(8)$ & $0.50(2)$ \\
\hline $\mathrm{Mg}$ & $0,\left[N_{A_{\mathrm{e}}}=0.72(17)\right]^{*}$ & 0 & $\infty$ & {$\left[\lambda_{\mathrm{e}}=0.58(3)\right]^{* *}$} & $0.28(15)$ & $0.26(7)$ \\
\hline $\mathrm{K}$ & $0.74(2)$ & $0.107(3)$ & $3.07(3)$ & $0.44(2)$ & $0.26(2)$ & $0.36(2)$ \\
\hline $\mathrm{Ca}$ & $0.72(2)$ & $0.094(12)$ & $3.20(13)$ & $0.52(11)$ & $0.28(2)$ & $0.24(4)$ \\
\hline
\end{tabular}



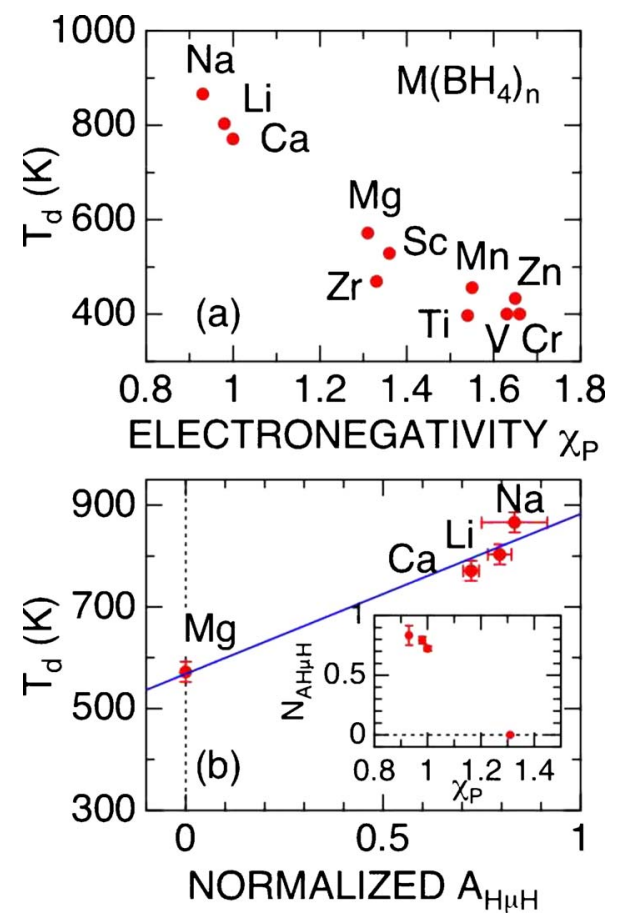

FIG. 4. (Color online) The relationship between (a) hydrogen desorption temperature $\left(T_{\mathrm{d}}\right)$ and electronegativity $\left(\chi_{\mathrm{P}}\right)$ (Ref. 23) and (b) $T_{\mathrm{d}}$ and $N_{A_{\mathrm{H} \mu \mathrm{H}}}$. The inset of (b) shows the relationship between $N_{A_{\mathrm{H} \mu \mathrm{H}}}$ and $\chi_{\mathrm{P}}$. Note that $T_{\mathrm{d}}$ for $\mathrm{KBH}_{4}$ was not reported in Ref. 23. high $N_{A_{\mathrm{H} \mu \mathrm{H}}}$ compared with that for the materials with low $N_{A_{\mathrm{H} \mu \mathrm{H}}}$. This is a reasonable explanation for the linear relationship in Fig. 4(b). Furthermore, such relationship is consistent with the result that the Ti doping reduces both $N_{A_{\mathrm{H} \mu \mathrm{H}}}$ and $T_{\mathrm{d}}$ for $\mathrm{NaAlH}_{4} \cdot{ }^{15}$ This also demonstrates that $\mu^{+} \mathrm{SR}$ is a unique tool for investigating the nature of $\mathrm{LiBH}_{4}$ and related hydrogen storage materials via the $\mathrm{H} \mu \mathrm{H}$ signal. Finally, we wish to emphasize that, although the relationship between $T_{\mathrm{d}}$ and $\chi_{\mathrm{P}}$ was found empirically for $M\left(\mathrm{BH}_{4}\right)_{n}$ [Fig. 4(a)], the underlying mechanism has been successfully clarified by the present $\mu^{+}$SR experiment. In fact, there was no experimental evidence regarding which parameters were predominant for determining $T_{\mathrm{d}} \cdot \mu^{+} \mathrm{SR}$ is, therefore, a unique tool to investigate the thermal stability of $M\left(\mathrm{BH}_{4}\right)_{n}$ and related compounds.

This work was performed at TRIUMF, Vancouver, Canada and we are thankful to the staff of TRIUMF for help with the $\mu^{+}$SR experiments. J.H.B. is supported at UBC by CIfAR, by NSERC of Canada, and (through TRIUMF) by NRC of Canada, and K.H.C. by NSERC of Canada and (through TRIUMF) by NRC of Canada. This work is partially supported by the NEDO "Development for Hydrogen Production, Transportation and Storage System" Project. All images involving crystal structure were made with a computer program VESTA. *e0589@mosk.tytlabs.co.jp

Present address: Muon Science Laboratory, Institute of Materials Structure Science, KEK, 1-1 Oho, Tsukuba, Ibaraki 305-0801, Japan.

${ }^{1}$ L. Schlapbach and A. Züttel, Nature (London) 414, 353 (2001).

${ }^{2}$ S. Orimo, Y. Nakamori, J. R. Eliseo, A. Züttel, and C. M. Jensen, Chem. Rev. 107, 4111 (2007).

${ }^{3}$ A. Züttel, A. Borgschulte, and S. Orimo, Scr. Mater. 56, 823 (2007).

${ }^{4}$ S. Orimo, Y. Nakamori, N. Ohba, K. Miwa, M. Aoki, S. Towata, and A. Züttel, Appl. Phys. Lett. 89, 021920 (2006).

${ }^{5}$ S. J. Hwang, R. C. Bowman, Jr., J. W. Reiter, J. Rijssenbeek, G. L. Soloveichik, J.-C. Zhao, H. Kabbour, and C. C. Ahn, J. Phys. Chem. C 112, 3164 (2008).

${ }^{6}$ A. Züttel, P. Wenger, S. Rentsch, P. Sudan, Ph. Mauron, and Ch. Emmenegger, J. Power Sources 118, 1 (2003).

${ }^{7}$ N. Ohba, K. Miwa, M. Aoki, T. Noritake, S. I. Towata, Y. Nakamori, S. I. Orimo, and A. Züttel, Phys. Rev. B 74, 075110 (2006).

${ }^{8}$ J. H. Brewer, S. R. Kreitzman, D. R. Noakes, E. J. Ansaldo, D. R. Harshman, and R. Keitel, Phys. Rev. B 33, 7813(R) (1986).

${ }^{9}$ K. Nishiyama, S. W. Nishiyama, and W. Higemoto, Physica B 326, 41 (2003).

${ }^{10}$ J. Sugiyama, RIKEN-RAL Muon Facility Report No. 6, 62, 2004-2006 (unpublished).

${ }^{11}$ T. Lancaster, S. J. Blundell, P. J. Baker, W. Hayes, S. R. Giblin, S. E. McLain, F. L. Pratt, Z. Salman, E. A. Jacobs, J. F. C. Turner, and T. Barnes, Phys. Rev. B 75, 220408(R) (2007).

${ }^{12}$ W. A. MacFarlane, D. Schick-Martin, M. Egilmez, I. Fan,
Q. Song, K. H. Chow, S. Cordier, C. Perrin, and S. D. Goren, Physica B 404, 622 (2009).

${ }^{13}$ P. Mendels, F. Bert, M. A. de Vries, A. Olariu, A. Harrison, F. Duc, J. C. Trombe, J. S. Lord, A. Amato, and C. Baines, Phys. Rev. Lett. 98, 077204 (2007).

${ }^{14}$ M. Månsson, Y. Ikedo, H. Nozaki, J. Sugiyama, P. L. Russo, D. Andreica, M. Shizuya, M. Isobe, and E. TakayamaMuromachi, Solid State Commun. 150, 307 (2010).

${ }^{15}$ R. Kadono, K. Shimomura, K. H. Satoh, S. Takeshita, A. Koda, K. Nishiyama, E. Akiba, R. M. Ayabe, M. Kuba, and C. M. Jensen, Phys. Rev. Lett. 100, 026401 (2008).

${ }^{16}$ B. Bogdanovic and M. Schwickardi, J. Alloys Compd. 253-254, 1 (1997).

${ }^{17}$ G. M. Kalvius, D. R. Noakes, and O. Hartmann, in Handbook on the Physics and Chemistry of Rare Earths, edited by K. A. Gschneidner, Jr., L. Eyring, and G. H. Lander (Elsevier Science B.V., Amsterdam, 2001), Vol. 32, Chap. 206, and references cited therein.

${ }^{18}$ K. Miwa, N. Ohba, S. I. Towata, Y. Nakamori, and S. I. Orimo, Phys. Rev. B 69, 245120 (2004).

${ }^{19}$ H. L. Johnston and N. C. Hallett, J. Am. Chem. Soc. 75, 1467 (1953).

${ }^{20}$ P. Fischer and A. Züttel, PSI Scientific Report Vol. III, g09, 2001 (unpublished).

${ }^{21}$ D. G. Allis and B. S. Hudson, Chem. Phys. Lett. 385, 166 (2004).

${ }^{22} P_{\mathrm{H} \mu}(t)=\frac{1}{6}+\frac{1}{6} \cos \left(\omega_{\mathrm{d}} t\right)+\frac{1}{3} \cos \left(\frac{1}{2} \omega_{\mathrm{d}} t\right)+\frac{1}{3} \cos \left(\frac{3}{2} \omega_{\mathrm{d}} t\right)$

${ }^{23}$ Y. Nakamori, K. Miwa, A. Ninomiya, H. Li, N. Ohba, S. I. Towata, A. Züttel, and S. I. Orimo, Phys. Rev. B 74, 045126 (2006). 